archives-ouvertes

\title{
Growth and characterization of Ge islands on $\mathrm{Si}(110)$
}

\author{
Philippe Ferrandis, L Vescan
}

\section{To cite this version:}

Philippe Ferrandis, L Vescan. Growth and characterization of Ge islands on $\mathrm{Si}(110)$. Materials Science and Engineering: B, Elsevier, 2002, 89 (1-3), pp.171-175. 10.1016/S0921-5107(01)00836-4 . hal-01616515

\section{HAL Id: hal-01616515 https://hal.archives-ouvertes.fr/hal-01616515}

Submitted on 13 Oct 2017

HAL is a multi-disciplinary open access archive for the deposit and dissemination of scientific research documents, whether they are published or not. The documents may come from teaching and research institutions in France or abroad, or from public or private research centers.
L'archive ouverte pluridisciplinaire HAL, est destinée au dépôt et à la diffusion de documents scientifiques de niveau recherche, publiés ou non, émanant des établissements d'enseignement et de recherche français ou étrangers, des laboratoires publics ou privés. 


\title{
Growth and characterization of $\mathrm{Ge}$ islands on $\mathrm{Si}\left(\begin{array}{lll}1 & 1 & 0\end{array}\right)$
}

\author{
P. Ferrandis ${ }^{\mathrm{a}, *}$, L. Vescan ${ }^{\mathrm{b}}$ \\ a Laboratoire de Physique de la matière, UMR CNRS 55II, INSA de Lyon, Bât. Blaise Pascal, 7 Avenue Jean Capelle, \\ 69621 Villeurbanne Cedex, France \\ ${ }^{\mathrm{b}}$ Forschungszentrum Juelich GmbH, Institut fuer Schichten und Grenzflächen, D-52425 Juelich, Germany
}

\begin{abstract}
The structural and optical properties of self-assembled Ge dots grown on $\operatorname{Si}\left(\begin{array}{lll}1 & 1 & 0\end{array}\right)$ substrates by low pressure chemical vapour deposition have been studied. A monomodal island size distribution with multifaceted domes has been determined from an atomic force microscopy characterization. An analysis of the island size provided information on the strain in islands. Thus, dome shape islands appear on our samples as elastically relaxed. Photoluminescence spectroscopy investigations as a function of temperature and excitation power allowed to identify two broad lines, which are respectively attributed to the wetting layer and the islands emissions. A good hole confinement allowing excitonic recombinations has also been pointed out. O 2002 Elsevier Science B.V. All rights reserved.
\end{abstract}

Keywords: Si(1 10 ); Ge; Islands; Low pressure chemical vapour deposition; Atomic force microscopy; Photoluminescence

\section{Introduction}

The achievement of efficient optoelectronic devices fully integrated on $\mathrm{Si}$ for the communication wavelengths 1.3 and $1.55 \mu \mathrm{m}$ is a research subject of great interest. Such components would allow a significant cost reduction in fabrication processes. A possible approach to produce an intense luminescence is to use Ge nanostructures embedded in $\mathrm{Si}$. The localization of excitons into Ge islands is actually expected to increase the light emission.

Several Si surface orientations have been studied like

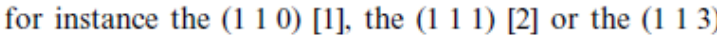
[3]. The $\left(\begin{array}{lll}1 & 1 & 0\end{array}\right)$ orientation provides advantages, which might be interesting for the growth of self-assembled Ge dots. Indeed, the structural anisotropy of the $\mathrm{Si}\left(\begin{array}{lll}1 & 1 & 0\end{array}\right)$ surface may influence the nucleation of coherent $\mathrm{Ge}$ islands. Furthermore, a better electron confinement compared to $\mathrm{Ge}$ deposition on $\mathrm{Si}\left(\begin{array}{lll}0 & 0 & 1\end{array}\right)$ is predicted with a type I alignment due to lower conduction band edge [4]. From a technological point of view, the $\left(\begin{array}{lll}1 & 1 & 1\end{array}\right)$ cleavage plane perpendicular to the $\left(\begin{array}{lll}1 & 1 & 0\end{array}\right)$ surface may simplify the fabrication of waveguide structures.

In this paper, we present the characterization of $\mathrm{Ge}$ islands grown on $\mathrm{Si}\left(\begin{array}{lll}1 & 1 & 0\end{array}\right)$ substrates. Morphological and optical investigations allowed to emphasize the properties of these islands.

\section{Experimental}

Epilayers were grown on n-type $\left(\begin{array}{lll}1 & 1 & 0\end{array}\right)$ oriented $\mathrm{Si}$ substrates (resistivity $1-10 \Omega \mathrm{cm}$ ) in a low pressure chemical vapour deposition (LPCVD) reactor. The growth was carried out at 0.12 Torr using respectively, $\mathrm{SiCl}_{2} \mathrm{H}_{2}$ and He-diluted $\mathrm{GeH}_{4}$ as source gases for silicon and germanium epitaxy. After the deposition of a $\approx 250 \mathrm{~nm}$ thick $\mathrm{Si}$ buffer layer at $800{ }^{\circ} \mathrm{C}$, Ge dot structures were grown at $700{ }^{\circ} \mathrm{C}$ with a constant pure $\mathrm{GeH}_{4}$ flow of $1 \mathrm{sccm}$. Samples used for photoluminescence (PL) investigations were capped by a $\mathrm{Si}$ layer deposited at $700{ }^{\circ} \mathrm{C}$ for $60 \mathrm{~min}$ in order to avoid non-radiative recombinations, which could take place at the surface of Ge islands. No annealing steps were performed between layer depositions and samples were cooled after epitaxy with a cooling rate of $1 \mathrm{~K} / \mathrm{s}$. 
The surface topography was investigated with a Digital Instruments Nanoscope IIIa atomic force microscopy (AFM) in tapping mode on samples without cap layer. PL measurements were carried out using the $514.5 \mathrm{~nm}$ emission line of an Argon-ion laser. A beam focused with a $200 \mu \mathrm{m}$ diameter was used as excitation source. Luminescence was dispersed by a HRS2 JobinYvon monochromator and detected by a liquid-nitrogen cooled Ge detector (Applied Detector Corporation 403L I-R). Rutherford backscattering spectroscopy (RBS) analysis allowed to determine the total Ge amount deposited.

\section{Results and discussion}

A set of seven samples with various Ge coverage was performed on $\mathrm{Si}\left(\begin{array}{lll}1 & 1 & 0\end{array}\right)$ substrates. Ge thicknesses were determined from RBS analysis and are in the range of
$0.48-2.07 \mathrm{~nm}$. The two- to three-dimensional transition has occurred for a Ge thickness $\leqslant 1.07 \mathrm{~nm}$. In this work, we focus the discussion on sample 1677b (Ge thickness $=1.07 \mathrm{~nm}$ ) and sample $1680 \mathrm{~b}$ (Ge thickness $=2.07 \mathrm{~nm}$ ). Fig. 1 presents a $1 \times 1 \mu^{2}$ AFM image from sample $1677 \mathrm{~b}$ (see Table 1 for details). A statistic island size distribution reveals that only one kind of island exists. They are domes, which can be easily identified due to their rounded shape, their macroscopic size and their multiple equilibrium facets [5]. Sample 1677b was grown with a Ge deposition time of $55 \mathrm{~s}$, which corresponds to the smallest Ge coverage where islands appear. Thus, a monomodal island size distribution seems already to take place at an early stage of island formation on $\operatorname{Si}\left(\begin{array}{lll}1 & 1 & 0\end{array}\right)$.

Capellini et al. [6] have shown by comparing AFM topographs and cross-sectional transmission electron microscope (TEM) micrographs that there is a link between morphology and strain in the islands. When

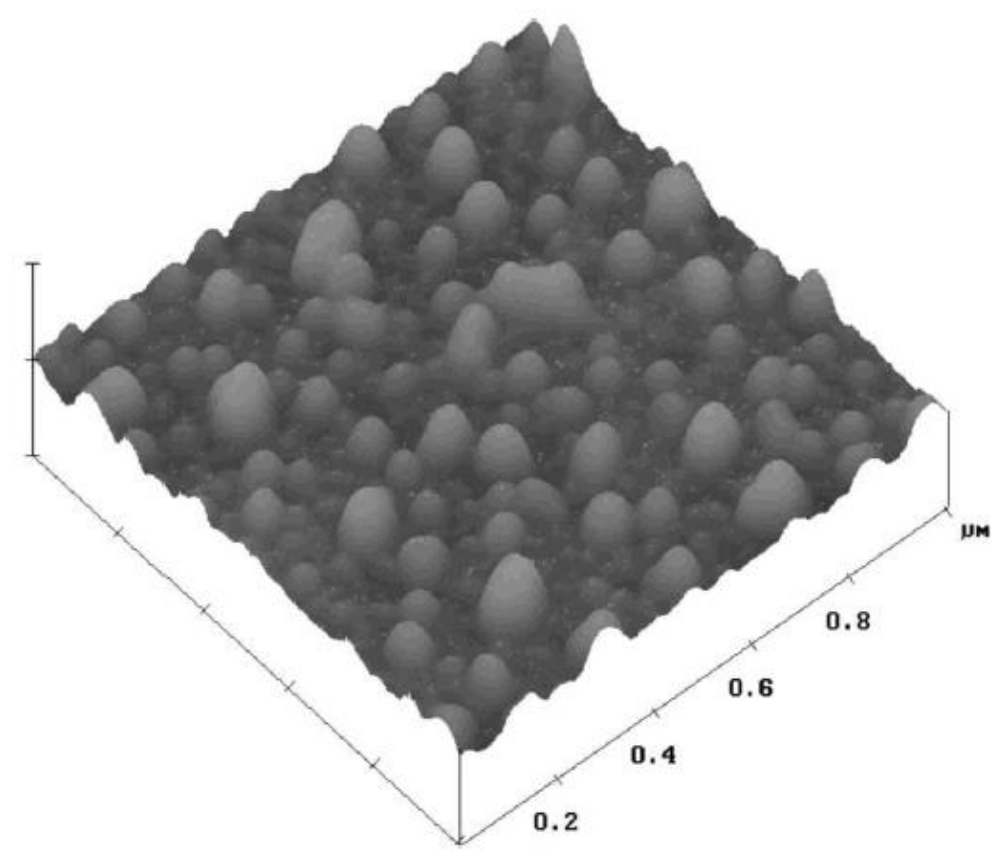

Fig. 1. AFM image from sample $1677 \mathrm{~b}$ (the Ge equivalent thickness is $1.07 \mathrm{~nm}$ ), we observe a monomodal island size distribution formed by dome shape islands.

Table 1

Detailed features of samples $1677 \mathrm{~b}$ and $1680 \mathrm{~b}$

\begin{tabular}{lllll}
\hline $\begin{array}{l}\text { Sample } \\
\text { name }\end{array}$ & $\begin{array}{l}\text { Ge deposition } \\
\text { time }\end{array}$ & $\begin{array}{l}\text { Ge thickness } \\
(\mathrm{nm})(\mathrm{RBS})\end{array}$ & $\begin{array}{l}\text { Island area } \\
\text { density }\left(\mu \mathrm{m}^{-2}\right)\end{array}$ & $\begin{array}{l}\text { Average island height } \\
(\mathrm{nm})\end{array}$ \\
\hline $1677 \mathrm{~b}$ & $55 \mathrm{~s}$ & 1.07 & 81 & 16 \\
$1680 \mathrm{~b}$ & $1 \mathrm{~min} 51 \mathrm{~s}$ & 2.07 & 84 & 22
\end{tabular}

The Ge thickness was determined from RBS analysis. Densities and average island sizes were deducted from AFM investigations. 


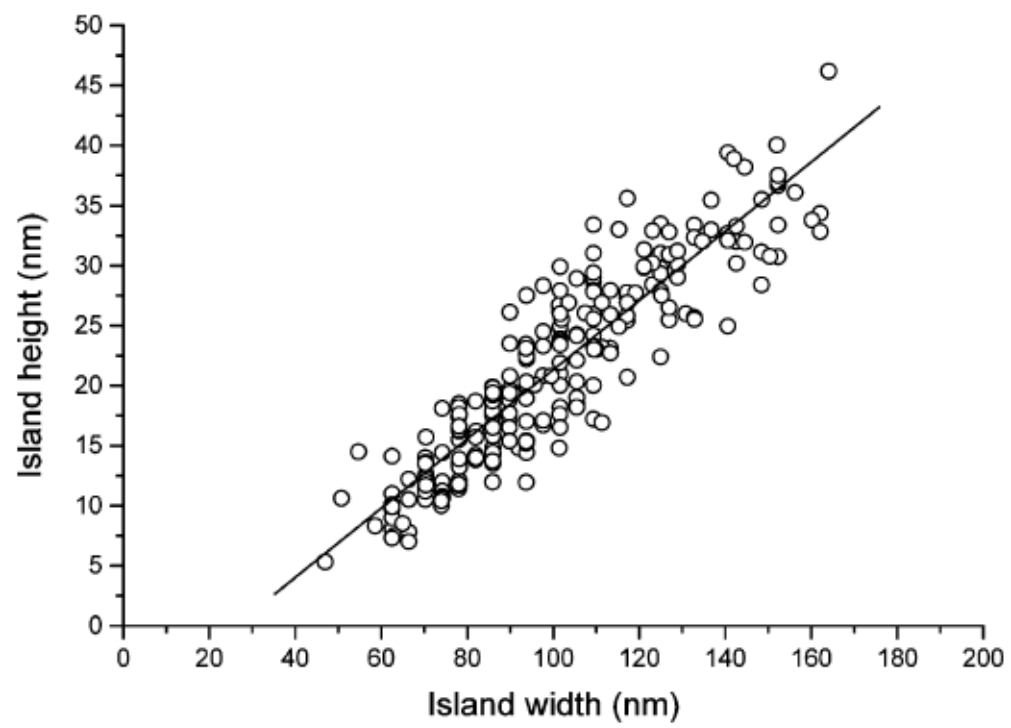

Fig. 2. Island heights as a function of island base widths. This graph is realized with samples with various coverages. Each point corresponds to one island. The solid line results from a linear fit.

plastic relaxation takes place, TEM micrographs exhibit dislocations, which develop from the islands edge toward the centre of the structure. This produces an increase of island widths, which can be revealed by AFM analysis. A plot of island height as a function of island base width should show a line whose slope depends on the strain in islands. As plastically relaxed islands have an enhanced width due to the presence of dislocations, the slope originated from such islands should be found lower than the slope determined from elastically relaxed islands. Fig. 2 is a scatter plot of the island height versus diameter. This graph was carried out from samples with a growth time between $55 \mathrm{~s}$ and $1 \mathrm{~min} 51 \mathrm{~s}$. It appears clearly that only one slope can be extracted as shown by the solid line. Consequently, we conclude that islands on these samples are mainly free of dislocations.

On the other hand, it is interesting to note that the solid line in Fig. 2 determined by a linear fit does not extrapolate to zero. This trend is due to the type of islands involved, which are only domes. A second island phase should appear with a base width between 0 and $50 \mathrm{~nm}$ [7]. These nanostructures should exhibit a different height to diameter ratio and should therefore provide a smaller linear fit slope, which would go through zero. However, such islands are not stable and are difficult to observe on $\mathrm{Si}(110)$, at least in our growth conditions. As a consequence, they do not appear in Fig. 2.

Table 1 summarizes detailed features for two deposition times. While densities are approximately similar for both samples, larger islands were found on sample $1680 \mathrm{~b}$ due to the higher Ge thickness. However, the nanocrystal size compared to island area density seems inconsistent with pure Ge islands. In a precedent work on $\mathrm{Si}\left(\begin{array}{l}0 \\ 0\end{array}\right)$, a detailed study on a sample performed under the same growth conditions as our samples has been reported [8]. The Ge thickness determined from RBS analysis was $1 \mathrm{~nm}$ and the island area density was $4 \mu \mathrm{m}^{-2}$ for an average island height of $28 \mathrm{~nm}$. By comparing these results with data on sample $1677 \mathrm{~b}$ (see Table 1), we remark that with a similar Ge thickness $(1.07 \mathrm{~nm})$ our sample on $\mathrm{Si}\left(\begin{array}{lll}1 & 1 & 0\end{array}\right)$ exhibits an island area density much larger $\left(81 \mu \mathrm{m}^{-2}\right)$ while the average island height is not extremely attenuated $(16 \mathrm{~nm})$. The difference between island sizes cannot explain the number of clusters found 20 times higher on our sample. Thus, the obvious conclusion is that many $\mathrm{Si}$ atoms have moved into the Ge islands and have formed a $\mathrm{SiGe}$ alloy. Consequently, a stronger $\mathrm{Si}$ content in islands on $\mathrm{Si}\left(\begin{array}{lll}1 & 1 & 0\end{array}\right)$ is expected compared with the one in islands on $\operatorname{Si}\left(\begin{array}{lll}0 & 0 & 1\end{array}\right)$.

Fig. 3 shows PL spectra from capped sample $1680 \mathrm{~b}$ measured at 9, 70 and $300 \mathrm{~K}$. The PL emission of $\mathrm{Si}$ layers is not shown. At $9 \mathrm{~K}$, two peaks can be identified while only the peak at low energy is observed on spectra at higher temperature. The barrier for thermal emission is expected to be higher in relaxed islands than in the wetting layer due to the difference in band offsets and confinement energies [9]. Thus, the PL peak which vanishes early, when temperature increases, is attributed to the wetting layer emission. The position at higher energy of this peak is consistent with the previous consideration since the thickness of the wetting layer (that we estimate at $\approx 0.8 \mathrm{~nm}$ ) leads to a quantum confinement effect, which increases the interband 


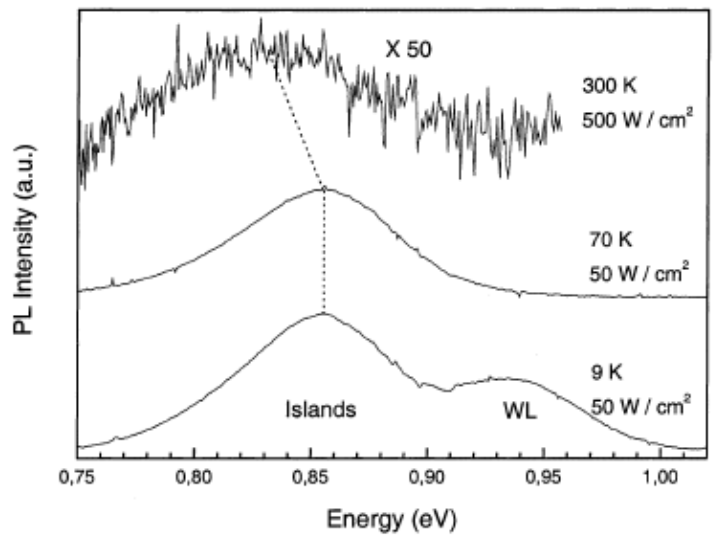

Fig. 3. PL spectra from capped sample 1680b. The lower spectrum performed at $9 \mathrm{~K}$ and $50 \mathrm{~W} / \mathrm{cm}^{2}$ exhibits two peaks due to the wetting layer (WL) and the island PL emission. The two upper spectra were carried out respectively at $70 \mathrm{~K}, 50 \mathrm{~W} / \mathrm{cm}^{2}$ and $300 \mathrm{~K}$, $500 \mathrm{~W} / \mathrm{cm}^{2}$. They show only one peak coming from islands PL signal.

recombination energy. Even with an enhanced Si content as resulting from AFM investigations, islands PL emission is still detectable at $300 \mathrm{~K}$. This means that the lower Ge composition does not contribute sufficiently to reduce the valence band offset and allows to keep a good hole confinement.

To study the PL peak from islands in detail, we have investigated the excitation power dependence of this peak as shown in Fig. 4. A temperature of $70 \mathrm{~K}$ was chosen to avoid the wetting layer PL contribution while keeping the presence of excitons. The widening of the peak when the excitation power increases from 1 to $3000 \mathrm{~W} / \mathrm{cm}^{2}$ and the shift towards higher energies result from a band filling effect [10].

In Fig. 5, we have plotted the integrated PL intensity of the island PL peak against the excitation power. Results were fitted with Eq. (1)

$I_{\mathrm{PL}} \propto P^{m}$,

where $I_{\mathrm{PL}}$ is the integrated PL intensity, $P$ is the excitation power and $m$ is the power exponent. The slope $m=0.79$ is smaller than 1 which is the expected value for pure excitonic recombinations. This slightly sublinear exponent cannot be explained by bounded exciton recombinations since all excitons are free at $70 \mathrm{~K}$. This indicates that non-radiative pathways consumes carriers [11]. However, $m$ remains constant between 1 and 3000 $\mathrm{W} / \mathrm{cm}^{2}$. This trend has already be observed by others authors [11] and reveals that non-radiative channels have been quenched. Consequently, the luminescence comes mainly from radiative recombinations.

\section{Conclusion}

Ge islands have been grown on $\operatorname{Si}\left(\begin{array}{lll}1 & 1 & 0\end{array}\right)$ substrates. Their structural and optical properties were determined from AFM and PL investigations. A monomodal island size distribution shows the presence of only one kind of nanostructures, which are multifaceted domes. A plot of the height as a function of the base width reveals that islands are mainly free of dislocations. The evolution of PL spectra versus the temperature and the excitation power allows to identify PL peaks and to

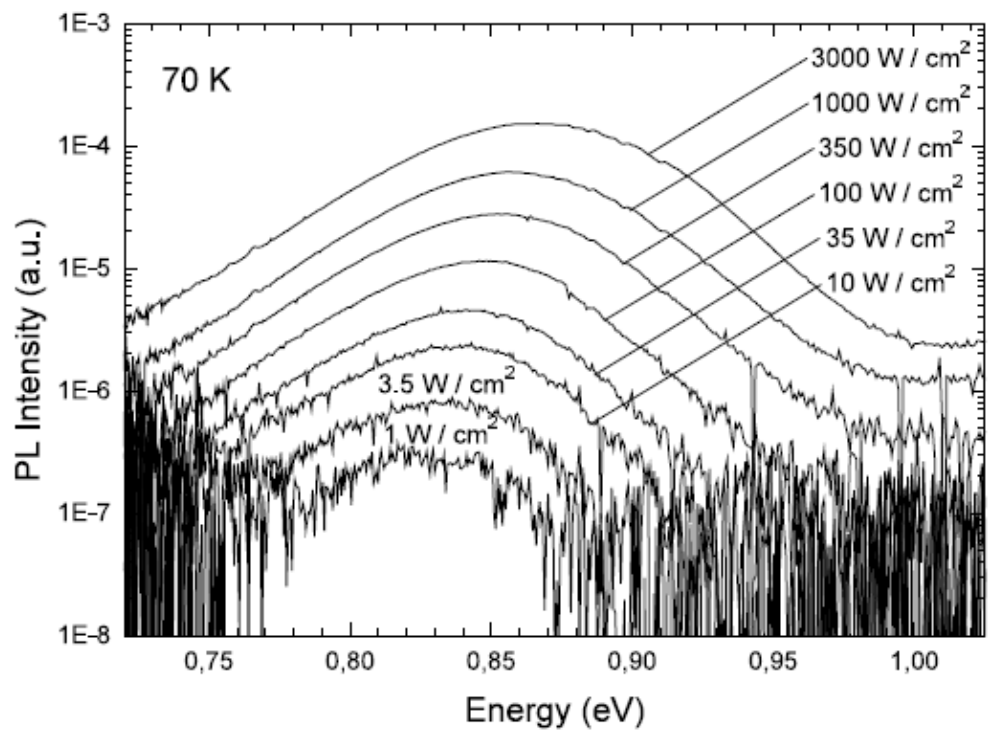

Fig. 4. Evolution of the sample capped $1680 \mathrm{~b}$ spectrum as a function of the excitation laser power at $70 \mathrm{~K}$ (capped sample $1680 \mathrm{~b}$ ). 


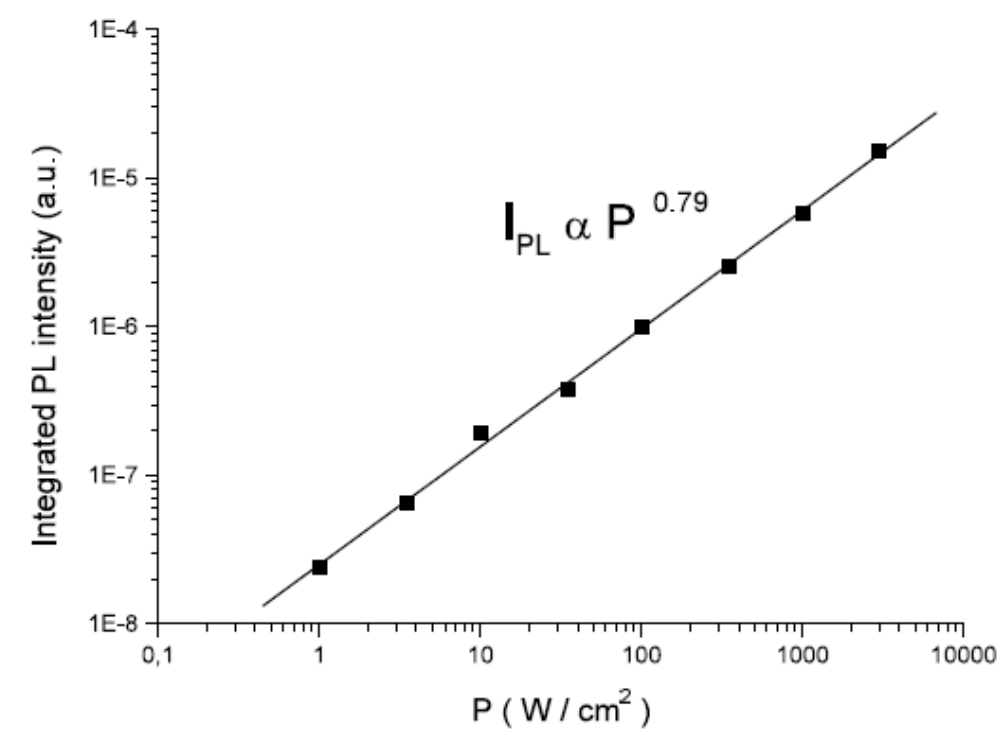

Fig. 5. Excitation power dependence of integrated PL intensity for capped sample 1680b. This graph is deducted from spectra shown in Fig. 4 . The slope $m=0.79$ reveals the presence of non-radiative channels.

conclude that the island luminescence comes from excitonic recombinations. Although AFM investigations have shown that islands have an enhanced $\mathrm{Si}$ content, the PL of these islands is still observable at room temperature.

\section{Acknowledgements}

The authors would like to thank B. Holländer for Rutherford backscattering analysis and are indebted to the TMR Network Aapples No. FMRXCT96-0029 for the financial support.

\section{References}

[1] M. Krishnamurthy, Bi-Ke Yang, J.D. Weil, C.G. Slough, Appl. Phys. Lett. 70 (1997) 49.
[2] P.D. Persans, P.W. Deelman, K.L. Stokes, L.J. Schowalter, A. Byrne, T. Thundat, Appl. Phys. Lett. 70 (1997) 472.

[3] J.-H. Zhu, C. Miesner, K. Brunner, G. Abstreiter, Appl. Phys. Lett. 75 (1999) 2395.

[4] C.G. Van de Walle, R.M. Martin, Phys. Rev. B 34 (1986) 5621.

[5] D.J. Eaglesham, M. Cerullo, Phys. Rev. Lett. 64 (1990) 1943.

[6] G. Capellini, L. Di Gaspare, F. Evangelisti, E. Palange, A Notargiacomo, C. Spinella, S. Lombardo, Semicond. Sci. Technol. 14 (1999) L21

[7] G. Capellini, L. Di Gaspare, F. Evangelisti, E. Palange, Appl. Phys. Lett. 70 (1997) 493.

[8] M. Goryll, L. Vescan, H. Lüth, Mater. Sci. Eng. B 69-70 (2000) 251.

[9] L. Vescan, M. Goryll, T. Stoica, P. Gartner, K. Grimm, O. Chretien, E. Mateeva, C. Dieker, B. Holländer, Appl. Phys. A 71 (2000) 423.

[10] J.C. Sturm, A. St. Amour, Q. Mi, L.C. Lenchyshyn, M.L.W Thewalt, Jpn. J. Appl. Phys. 33 (1994) 2329.

[11] S. Fukatsu, N. Usami, Y. Shiraki, J. Vac. Sci. Technol. B 11 (1993) 895 . 